\title{
Monogenic diabetes due to an INSR mutation in a child with severe insulin resistance
}

\author{
Elaine E Sanderson (D1, Mark Shah', Amanda J Hooper2,3, Damon A Bell2,3 and \\ Catherine S Choong ${ }^{1,3}$
}

1Department of Endocrinology and Diabetes, Perth Children's Hospital, Perth, Western Australia, Australia, 2Department of Clinical Biochemistry, PathWest Laboratory Medicine WA, Royal Perth Hospital and Fiona Stanley Hospital Network, Perth, Australia, and ${ }^{3}$ School of Medicine, University of Western Australia, Perth, Australia

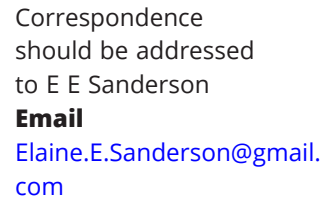

Elaine.E.Sanderson@gmail. com

\section{Summary}

We report a case of an 11-year-old girl presenting with a new diagnosis of diabetes associated with a heterozygous missense mutation in the insulin receptor (INSR) gene. This case highlights that INSR gene variants can be a cause for monogenic diabetes in children and adolescents and the need for genetic evaluation in atypical presentations of diabetes. We also describe the possible role of metformin in treating individuals with type A insulin resistance syndrome due to INSR gene variants.

\section{Learning points:}

- Insulin receptor (INSR) gene variants can be a cause of monogenic diabetes in children and adolescents.

- Genetic evaluation should be considered in children and adolescents with type 2 diabetes (T2D), particularly where there is an atypical presentation and/or positive family history.

- Metformin may have a role in the treatment of type A insulin resistance syndrome due to heterozygous mutation of the INSR gene.

\section{Background}

Monogenic diabetes is an autosomal, dominantly inherited condition and is increasingly being identified as a cause for diabetes in children and adolescents (1). While prevalence varies between populations, it is estimated that monogenic diabetes contributes to $1-2 \%$ of diagnosed diabetes cases in children and adolescents (1). At least 30 genes have been implicated in monogenic diabetes, and the most commonly seen genetic mutations being those associated with maturity-onset diabetes of the young and occurring in hepatocyte nuclear factor (HNF1A), glucokinase (GCK) or $\operatorname{HNF} 4 A(1,2,3)$.

Mutations in the INSR gene resulting in severe insulin resistance and hyperglycaemia are a less common cause of monogenic diabetes in children and adolescents $(4,5)$. Over 150 INSR genetic variants have been identified resulting in a spectrum of insulin resistance syndromes of varying severity, including Donohue syndrome, RabsonMendenhall syndrome and type A insulin resistance syndrome; a syndromic form of diabetes that can present in childhood or early adulthood $(1,6)$.

Genetic testing for monogenic causes of diabetes has become increasingly available for patients with diabetes $(2,7)$ and should be considered in patients presenting with hyperglycaemia who have at least two generations of family members diagnosed with diabetes before 25 years of age and negative islet-cell antibodies $(8,9)$.

We report a case of an 11-year-old girl presenting with severe insulin resistance and hyperglycaemia meeting criteria for diabetes, associated with a heterozygous missense mutation, His1157Arg, in the INSR gene. 


\section{Case presentation}

An 11-year-old Caucasian girl was referred to outpatient paediatric endocrinology for evaluation of severe acanthosis nigricans and hyperinsulinaemia. She was born via vaginal delivery at term, following an uncomplicated pregnancy, with a weight of $2.268 \mathrm{~kg}$ (5.0 pounds; $<5$ th centile). Her past medical history included a presumed urinary tract infection at 5 weeks of age, tonsillectomy at 4 years of age and possible Kawasaki disease.

The patient's mother had been concerned regarding acceleration in weight, particularly of the abdominal region in the 2 years preceding her initial endocrinology consultation. For the same period of time, her mother had noted an 'axillary rash' confirmed as acanthosis nigricans on examination. Family history was significant for T2D in a number of second-degree relatives on both sides of the family including her paternal grandmother.

Her height was $146.8 \mathrm{~cm}$ (50th centile; consistent with mid-parental height 25th-50th centile) and weight $69 \mathrm{~kg}$ ( $>97$ th centile) with BMI $32 \mathrm{~kg} / \mathrm{m}^{2}$ (>97th centile). Her blood pressure was 118/71 (95th-97th centile). She was Tanner stage 2 for pubic hair and breast development with mild clitoromegaly. There was marked acanthosis in the axillary and inguinal regions. Hirsutism and acne, other clinical signs of hyperandrogenism, were not evident on examination.

\section{Investigation}

The following investigations were organised; glycated haemoglobin (HbA1c), fasting insulin, full blood count, iron studies, $24 \mathrm{~h}$ urinary cortisol, follicle-stimulating hormone (FSH), luteinising hormone (LH), thyroid function test, liver function test, fasting lipids and bone age.

Her HbA1c was markedly elevated at 9.2\% consistent with a diagnosis of diabetes (HbA1c > 6.5\%) despite two previously normal fasting blood glucose levels in the prior months. In addition, her fasting insulin was markedly elevated at $220 \mathrm{mU} / \mathrm{L}(<12)$ and C peptide 2.10 $\mathrm{nmol} / \mathrm{L}(0.2-0.9)$ with concomitant fasting glucose of $4.8 \mathrm{mmol} / \mathrm{L}$. Alanine aminotransferase (ALT) and FSH were both mildly elevated at $34 \mathrm{U} / \mathrm{L}(<30)$ and $7 \mathrm{U} / \mathrm{L}$ $(<6)$, respectively. Other results were normal, and there was no evidence of haemoglobinopathy. Her bone age was concordant with her chronological age, and she had normal urinary cortisol levels that made a diagnosis of simple virilising congenital adrenal hyperplasia less likely.

\section{Treatment}

Following these results, the patient was admitted to the hospital for glucose profiling for $24 \mathrm{~h}$ with blood glucose readings $3.9-8.7 \mathrm{mmol} / \mathrm{L}$. She was commenced on metformin $500 \mathrm{mg}$ XR once a day, and both she and her family received education regarding lifestyle modifications. Within 2 weeks of commencing treatment, her HbA1c had improved to $7.9 \%$; there was no evidence to suggest her haemoglobin had decreased and may have affected this result. Her blood pressure was also normotensive at 100/60.

\section{Outcome and follow-up}

This patient did not have a first-degree relative with diabetes; however, her young age, normal fasting blood glucose in the setting of severe insulin resistance with markedly elevated insulin levels, absence of other features commonly seen with type 2 diabetes (hyperlipidaemia and/or deranged liver function) and strong family history of second-degree relatives diagnosed with diabetes at a young age, raised the possibility of a monogenic cause for diabetes. Genetic testing was performed with consent from her father. Massively parallel sequencing using a custom cardiometabolic gene panel with targeted analysis of monogenic diabetes genes (HNF4A, GCK, HNF1A, PDX1, HNF1B, NEUROD1, CEL, INS, ABCC8, KCNJ11, INSR, PLIN1, $P P A R G, L M N A$ ) identified a heterozygous INSR missense variant (a variant in one copy of the INSR gene while the other was normal) in exon 19, NM_000208.4(INSR): c.3470A $>$ G, p.(His1157Arg). The variant was classified as 'likely pathogenic' according to the 2015 American College of Medical Genetics and Genomics criteria (10) based on the variant's absence from the gnomAD population database; its presence, in other cases, that insulin resistance due to INSR gene variants has a specific phenotype and is mainly caused by missense variants and that in silico algorithms predict an effect of the variant on INSR protein function. The patient and her family were referred for genetic counselling, though, to date, neither parent has had genetic testing performed. However, as neither parent has been diagnosed with diabetes or insulin resistance, we speculate the variant has occurred de novo.

Three months after her initial diagnosis, the patient's HbA1c had further improved to $6.0 \%$ with $500 \mathrm{mg}$ metformin XR and lifestyle modifications. Her weight remained stable at $68.3 \mathrm{~kg}$ (previously $69 \mathrm{~kg}$ at initial visit). During this appointment, she described symptoms suggestive of hypoglycaemia on a number of occasions (shakiness and light-headedness) that improved with food 
intake, an unusual phenomenon on metformin alone. Unfortunately, no blood glucose levels were taken at this time to provide confirmation of hypoglycaemia; however, she has been instructed to perform a blood glucose check prior to any oral intake in case of a further event.

\section{Discussion}

We report the case of an 11-year-old girl presenting with severe insulin resistance and hyperglycaemia due to a heterozygous INSR mutation. The His1157Arg missense variant in exon 19 , while absent from gnomAD population database ( 250000 alleles), has been described in the literature previously in two sisters who had presented with severe insulin resistance at ages 15 and 11 years (11). Due to the legacy numbering of amino acids, the variant was previously referred to as His1130Arg (11). In an Iranian study seeking to identify INSR variants in T2D patients, a similar variant affecting the same amino acid, p.His1157Gln, was found in two patients, but clinical details were not included (12). The INSR gene is located on autosome 19, and its product consists of two alpha-subunits and two beta subunits (13). Exons 12-22 encode the beta subunit and mutations in this result in inhibition or decrease of tyrosine kinase activity in the receptor signalling pathway (13).

Mutations in INSR have been implicated in the impairment of insulin signalling pathways resulting in severe insulin resistance syndromes $(13,14)$. Most INSR mutations have a dominant-negative effect, with the defective receptor interfering with normal receptor function (9). No strong genotype-phenotype correlation is evident (14); however, heterozygous mutations in the beta subunit, as seen in our case, are thought to result in a milder phenotype as seen in type A insulin resistance syndrome $(13,14)$. Type A insulin resistance syndrome has an incidence of 1 in 100 000, and clinical features include severe hyperinsulinaemia, hyperandrogenism and acanthosis nigricans (13). While our case did not have biochemical measurement of androgens performed, clinically she had features suggestive of hyperandrogenism (mild clitoromegaly) in addition to the other features of type A insulin resistance syndrome (severe hyperinsulinaemia and acanthosis nigricans). The clinical picture is usually more severe in females than males, and features typically appear at pubertal age, as occurred in the case patient $(9,13)$. This reflects what is already known regarding insulin resistance and its relationship to puberty; the peak age for children to be diagnosed with T2D is mid-puberty (15). During puberty, there is an increase in growth hormone secretion and it is believed this causes insulin resistance
(15). Further, insulin resistance has been shown to be greater in females than males from early childhood to midpuberty (16).

Early in the disease process, postprandial hypoglycaemia may occur secondary to hyperinsulinaemia (13). Diabetes occurs when beta-cell function is unable to compensate for severe insulin resistance (17). Time to overt diabetes varies and has been reported as early as 9 years of age (18). However, in some patients, diabetes has not occurred until decades following the identification of an INSR mutation (17).

Due to the rarity of this variant, there are no guidelines to suggest optimal treatment. Metformin is an insulinsensitising agent that works to increase peripheral utilisation of glucose (19). Metformin potentiates the phosphatidylinositol-3' kinase pathway of insulin receptors, reducing insulin resistance and providing possible utility in the management of INSR mutations (19). However, it has been shown to have a variable effect in the treatment of type A insulin resistance syndrome due to beta-subunit mutations (19). An adolescent female with type A insulin resistance syndrome secondary to a missense variant in exon 17 , which also affects the beta subunit, showed an improvement in insulin resistance secondary to metformin treatment (19). Both androgen and insulin levels improved after the commencement of treatment in that case (19). Two other young females with severe insulin resistance secondary to insulin receptor mutations have also shown optimisation of glycaemic control with the initiation of metformin (20). The elder of the above-mentioned sisters with INSR His1157Arg was initially treated with GnRH agonist and metformin and when reached an appropriate age for puberty, estrogenprogestin pill and metformin (11). An oral glucose tolerance test (OGTT) was performed after the commencement of metformin; however, no favourable effect was seen (11). The second sister did not receive metformin as her older sister had shown insufficient efficacy in therapy (11). Our case was managed with metformin and lifestyle changes and showed an improvement in glycaemic control (9.2-6\%) within 3 months of diagnosis. This was in the setting of lifestyle modifications with weight maintenance, though no significant weight loss. A study investigating the glycaemic improvement of T2D children and adolescents treated with metformin (mean daily dose of $1798 \mathrm{mg}$ ) for 16 weeks showed an improvement in $\mathrm{HbA} 1 \mathrm{c}$ from $8.2 \% \pm 1.3 \%$ to $7.5 \% \pm 0.2 \%$ (19). Our case showed a much more dramatic improvement in HbA1c on a small dose (500 mg XR) in a similar timeframe (14 weeks). This suggests that metformin may have a role in patients with INSR variants.

The difference in glycaemic outcomes seen with the initiation of metformin in patients with INSR variants 
may be a result of residual beta-cell function at the time of commencement. In type 2 diabetes, metformin treatment failure is associated with lower beta-cell function (21). It is possible that our case patient may have had greater residual beta-cell function at metformin commencement compared to previous cases where metformin was shown to be ineffective. This is supported by the fact that some patients with INSR variants require high-dose insulin therapy in later stages of the disease process (20).

Despite hypoglycaemia being an uncommon side effect of metformin monotherapy, our patient described symptoms consistent with this at a follow-up appointment. Heterozygous mutations of the INSR gene, including those associated with type A insulin resistance syndrome, are commonly associated with hypoglycaemia postprandially, with multiple cases reported in the literature $(20,22)$. The mechanism behind this is thought to be due to decreased hepatic clearance of insulin and thus leading to hyperinsulinism (22).

Genetic evaluation for monogenic causes of diabetes is becoming more readily available and may enable more targeted management in patients and screening of family members (5). It has also seen patients' diagnoses reclassified and received a change in management (i.e. from insulin to oral hypoglycaemic agents) (5). The atypical features in this case (normal lipid profile, only mildly elevated ALT, normal fasting blood glucose) in the setting of severe insulin resistance prompted referral for genetic testing. This was despite most reported cases of monogenic diabetes being non-obese (1). The present study, however, found that $4.5 \%$ of overweight/obese children and adolescents with T2D had a monogenic cause for diabetes (23).

\section{Declaration of interest}

The authors declare that there is no conflict of interest that could be perceived as prejudicing the impartiality of the research reported.

\section{Funding}

This work did not receive specific grant from any funding agency in the public, commercial or not-for-profit sector.

\section{Patient consent}

Written informed consent was obtained from patient's parents.

\section{Author contribution statement}

E E S, M S, C S C contributed to clinical care. A J H, D A B performed genetic analysis, E E S wrote the manuscript. C S C oversaw all aspects of this report and edited the manuscript. All co-authors contributed to interpretation of the findings, critical revision of the manuscript and approved of its final content.

\section{Acknowledgements}

The authors thank Ms Lan Nguyen for her assistance with DNA sequencing and the patient and her family for permitting to submit this illustrative case.

\section{References}

1 Sanyoura M, Philipson LH \& Naylor R. Monogenic diabetes in children and adolescents: recognition and treatment options. Current Diabetes Reports 201818 58. (https://doi.org/10.1007/s11892-018-1024-2)

2 Pihoker C, Gilliam LK, Ellard S, Dabelea D, Davis C, Dolan LM, Greenbaum CJ, Imperatore G, Lawrence JM, Marcovina SM, et al. Prevalence, characteristics and clinical diagnosis of maturity onset diabetes of the young due to mutations in HNF1A, HNF4A, and glucokinase: results from the SEARCH for Diabetes in Youth. Journal of Clinical Endocrinology and Metabolism 201398 4055-4062. (https://doi. org/10.1210/jc.2013-1279)

3 Davis TM, Makepeace AE, Ellard S, Colclough K, Peters K, Hattersley A $\&$ Davis WA. The prevalence of monogenic diabetes in Australia: the Fremantle Diabetes Study Phase II. Medical Journal of Australia 2017 207 344-347. (https://doi.org/10.5694/mja16.01201)

4 Semple RK, Savage DB, Cochran EK, Gorden P \& O'Rahilly S. Genetic syndromes of severe insulin resistance. Endocrine Reviews 201132 498-514. (https://doi.org/10.1210/er.2010-0020)

5 Riddle MC, Philipson LH, Rich SS, Carlsson A, Franks PW, Greeley SAW, Nolan JJ, Pearson ER, Zeitler PS \& Hattersley AT. Monogenic diabetes: from genetic insights to population-based precision in care. Reflections from a diabetes care editors' expert forum. Diabetes Care 202043 3117-3128. (https://doi.org/10.2337/ dci20-0065)

6 INSR gene. 2014 18th Aug 2020 [cited 2020 31st Dec 2020]. (available at: https://medlineplus.gov/genetics/gene/insr/)

7 Peixoto-Barbosa R, Reis AF \& Giuffrida FMA. Update on clinical screening of maturity-onset diabetes of the young (MODY). Diabetology and Metabolic Syndrome 202012 50. (https://doi. org/10.1186/s13098-020-00557-9)

8 Lorini R, Klersy C, d'Annunzio G, Massa O, Minuto N, Iafusco D, Bellannè-Chantelot $\mathrm{C}$, Frongia AP, Toni S, Meschi F, et al. Maturity-onset diabetes of the young in children with incidental hyperglycemia: a multicenter Italian study of 172 families. Diabetes Care 200932 1864-1866. (https://doi.org/10.2337/dc08-2018)

9 Harraway J. Next generation sequencing to identify mutations causing maturity-onset diabetes of the young (MODY), 2011 [cited 2020 23rd Nov 2020]. (available from: https://www.rcpa.edu.au/ getattachment/095abf34-a2a4-45a1-bc4f-d02d2386562c/Dr-JamesHarraway-(Genetic-Pathology)-2011-RCPA-Fo.aspx)

10 Richards S, Aziz N, Bale S, Bick D, Das S, Gastier-Foster J, Grody WW, Hegde M, Lyon E, Spector E, et al. Standards and guidelines for the interpretation of sequence variants: a joint consensus recommendation of the American College of Medical Genetics and Genomics and the Association for Molecular Pathology .Genetics in Medicine 201517 405-424. (https://doi.org/10.1038/gim.2015.30)

11 Vambergue A, Lautier C, Valat AS, Cortet-Rudelli C, Grigorescu F \& Dewailly D. Follow-up study of two sisters with type A syndrome of severe insulin resistance gives a new insight into PCOS pathogenesis in relation to puberty and pregnancy outcome: a case report. Human Reproduction 200621 1274-1278. (https://doi.org/10.1093/humrep/ dei455)

12 Kazemi B, Seyed N, Moslemi E, Bandehpour M, Bikhof Torbati M, Saadat N, Eidi A, Ghayoor E \& Azizi F. Insulin receptor gene mutations in Iranian patients with type II diabetes mellitus. Iranian Biomedical Journal 200913 161-168.(PMID: https://pubmed.ncbi.nlm.nih. gov/19688022/

13 Lin L, Chen C, Fang T, Chen D, Chen K \& Quan H. Type A insulin resistance syndrome misdiagnosed as polycystic ovary syndrome: a 
case report. Journal of Medical Case Reports 201913 347. (https://doi. org/10.1186/s13256-019-2304-4)

14 Hosoe J, Kadowaki H, Miya F, Aizu K, Kawamura T, Miyata I, Satomura K, Ito T, Hara K, Tanaka M, et al. Structural basis and genotype-phenotype correlations of INSR mutations causing severe insulin resistance. Diabetes 201766 2713-2723. (https://doi.org/10.2337/db17-0301)

15 Reinehr T. Type 2 diabetes mellitus in children and adolescents. World Journal of Diabetes 20134 270-281. (https://doi.org/10.4239/wjd. v4.i6.270)

16 Huebschmann AG, Huxley RR, Kohrt WM, Zeitler P, Regensteiner JG $\&$ Reusch JEB. Sex differences in burden of type 2 diabetes and cardiovascular risk across the life course. Diabetologia 201962 1761-1772. (https://doi.org/10.1007/s00125-019-4939-5)

17 Rao G. Insulin resistance syndrome. American Family Physician 200163 1159-1163, 1165-1166.

18 Murphy R, Smith G, Isaac I, Hutchinson D \& Semple RK. Novel mutation in insulin receptor gene identified after muscle biopsy in a Niuean woman with severe insulin resistance. Diabetic Medicine 2015 32 e24-e28. (https://doi.org/10.1111/dme.12707)

19 Rique S, Ibáñez L, Marcos MV, Carrascosa A \& Potau N. Effects of metformin on androgens and insulin concentrations in type A insulin resistance syndrome. Diabetologia 200043 385-386. (https://doi. org/10.1007/s001250050059)

20 Wei C \& Burren CP. Diagnostic and management challenges from childhood, puberty through to transition in severe insulin resistance due to insulin receptor mutations. Pediatric Diabetes 201718 835-838. (https://doi.org/10.1111/pedi.12486)

21 Jeon JY, Lee SJ, Lee S, Kim SJ, Han SJ, Kim HJ, Kim DJ, Kim YS, Woo JT, Ahn KJ, et al. Failure of monotherapy in clinical practice in patients with type 2 diabetes: the Korean National Diabetes Program. Journal of Diabetes Investigation 20189 1144-1152. (https://doi.org/10.1111/ jdi.12801)

22 Innaurato S, Brierley GV, Grasso V, Massimi A, Gaudino R, Sileno S, Bernardini S, Semple R \& Barbetti F. Severe insulin resistance in disguise: a familial case of reactive hypoglycemia associated with a novel heterozygous INSR mutation. Pediatric Diabetes 201819 670-674. (https://doi.org/10.1111/pedi.12632)

23 Kleinberger JW, Copeland KC, Gandica RG, Haymond MW, Levitsky LL, Linder B, Shuldiner AR, Tollefsen S, White NH \& Pollin TI. Monogenic diabetes in overweight and obese youth diagnosed with type 2 diabetes: the TODAY clinical trial. Genetics in Medicine 201820 583-590. (https://doi.org/10.1038/gim.2017.150)

Received in final form 19 October 2021

Accepted 1 December 2021 